\title{
Advocating for the Retention of Positive Attributes of the Traditional Curriculum amidst the Transition to the Competency Based Curriculum in Medical Education Delivery
}

\author{
Shrivastava, S.R. ${ }^{1}$ \& Shrivastava, P.S. ${ }^{2}$
}

\begin{abstract}
Competency Based Medical Education (CBME) is the need of the hour in Indian settings and even though, the decision has come late, it is a step that needs to be appreciated and requires support from all the involved stakeholders for its successful implementation. However, it would be wrong to say that the traditional curriculum has offered no benefits for the students or faculty members. In conclusion, traditional curriculum has played a significant role in the development of medical graduates for more than two decades in India. Even though, some crucial aspects of professional growth have been ignored, it is still good enough to support the launch of CBME in India. As one among the faculty member, we have to take all the stakeholders on board and plan accordingly and at the same time not forget traditional curriculum, but build upon the advantages it has brought into the delivery of medical education.
\end{abstract}

Keywords: Traditional curriculum, Competency Based Medical Education, India

\section{Introduction}

Competency Based Medical Education (CBME) is the need of the hour in Indian settings and finally, after a wait of many years, the regulatory body has decided to make it happen for the undergraduate courses from the academic year 2019 (Medical Council of India, 2018).

${ }^{1}$ Vice-Principal Curriculum, Member of the Medical Education Unit and Institute Research Council, Department of Community Medicine, Shri Sathya Sai Medical College and Research Institute, Sri Balaji Vidyapeeth - Deemed to be University, Ammapettai, Nellikuppam, Chengalpattu, Kancheepuram, Tamil Nadu, India

${ }^{2}$ Department of Community Medicine, Shri Sathya Sai Medical College and Research Institute, Sri Balaji Vidyapeeth - Deemed to be University, Ammapettai, Nellikuppam, Chengalpattu, Kancheepuram, Tamil Nadu, India

Corresponding Author:

Dr. Saurabh RamBihariLal Shrivastava

Professor, Department of Community Medicine, Shri Sathya Sai Medical College and Research Institute, Sri Balaji Vidyapeeth (SBV) - Deemed to be University, Tiruporur - Guduvancherry Main Road, Ammapettai, Nellikuppam, Chengalpattu, Kancheepuram, Tamil Nadu 603108, India

Email: drshrishri2008@gmail.com
Even though, the decision has come late, it is a step that needs to be appreciated and requires support from all the involved stakeholders for its successful implementation (Medical Council of India, 2018). CBME in itself is a wonderful and a scientific approach to the curricular delivery and is built on the principles to develop a competent health care professional, but then at the same time neutralizes the demerits which have been attributed with the traditional curriculum (Medical Council of India, 2018; Powell \& Carraccio, 2018).

\section{Positive attributes of Traditional Curriculum}

However, it would be wrong to say that the traditional curriculum has offered no benefits for the students or faculty members (Ahmed \& Mubeen, 2013). Historically, our teachers and all the medical teachers have been a product of the traditional curriculum, without being exposed to CBME (Ahmed \& Mubeen, 2013). Even though, there were no outcomes defined for us at the start of the course (as it is being emphasized in CBME), the faculty members have been successful in acquiring most of the desired skills in their subject specialty (Powell

DOI: http://doi.org/10.4038/seajme.v13i2.205

(C) SEAJME. This is an Open Access article distributed under the terms of the Creative Commons Attribution
License (http://creativecommons.org/licenses/by/4.0/), which permits unrestricted use, distribution, and
reproduction in any medium, provided the original author and source are credited


\& Carraccio, 2018; Ahmed \& Mubeen, 2013). Even if the process of teaching-learning/ assessment was not objective, owing to the inherent merits of bedside teaching, role modeling and a dedicated approach, the faculty members are quite skilled (Ahmed \& Mubeen, 2013; De Oliveira, et al., 2018).

The driving force in the traditional curriculum has been content and knowledge acquisition, and as per the very famous saying, "The eyes see only what the mind knows", the entire focus is that the student gets good exposure of the content of the subject. So, the traditional curriculum teaches the student in quite the right way and builds upon the knowledge component. Further, traditional curriculum prepared students to see patients carefully, discuss and read about them, and learn to learn from each other and on their own. Moreover, learning has to happen in all the 3 domains of learning (viz. cognitive, psychomotor, affect), all of them requires a very strong support of knowledge component. In-fact, in the absence of a good knowledge component, it is very difficult to apply (as envisaged in the CBME), and thus traditional curriculum has played a major role in strengthening of the foundation stone (Ahmed \& Mubeen, 2013; De Oliveira, et al., 2018).

Often it has been said that in the traditional curriculum, the responsibility of the delivered content and the onus lies with the teacher and not the student (as in CBME), but to be frank, it is quite obvious and an encouraging aspect, as the teacher understands the current needs and has more experience as compared to the students, who are still finding their feet in the specialty of Medicine. The teacher can very well plan to deliver the right content at the right time and mould the career of students for their betterment and a good professional career (Ahmed \& Mubeen, 2013; De Oliveira, et al., 2018).

Another debatable issue has been the duration of the under-graduation course, which is fixed in the traditional curriculum, while in CBME it is not. To be frank enough, the entire duration in itself is quite long (5.5 years), as compared to any other professional course. Despite knowing this, the CBME has come with the concept of "Variable time", in which student has to continue their course till they acquire the set competencies. This will put students in immense pressure and it will become a big challenge for the students as they have to constantly read and perform, otherwise there is an every possibility that their course will be further extended. Are we right in doing that?? Is it not too much??

Even in traditional curriculum, though performance in the summative assessment exams aids in taking a high-stakes decision, it is very much supported by the formative assessments (cycle tests, practical exams, end posting exams, internal assessment, model/send-up exams), which together make the internal assessment, and definitely gets counted. It is not like that in traditional curriculum, there have been no formative assessments (Medical Council of India, 2018). Finally, coming to the implementation aspect of CBME, it has to be planned and executed in such a way that all the involved stakeholders should embrace it (Shrivastava \& Shrivastava, 2018). However, we have to first answer, where is the desired infrastructure support/ financial investment, how to design and who will design the assessment plan and then where are the human resources (faculty members)? (Medical Council of India, 2018; Shrivastava \& Shrivastava, 2018). On one side, a wide range of innovations has been proposed in teachinglearning / assessment (which all are advocated in CBME), while on the other hand, the regulatory body has reduced the number of faculty members required in an institute.

\section{Conclusion}

In conclusion, traditional curriculum has played a significant role in the development of medical graduates for more than two decades in India. Even though, some crucial aspects of professional growth have been ignored, it is still good enough to support the launch of CBME in India. As one among the faculty member, we have to take all the stakeholders on board and plan accordingly and at the same time not forget traditional curriculum, but build upon the advantages it has brought into the delivery of medical education.

\section{References}

Ahmed, S.D.H. \& Mubeen, S.M. (2013) Exploring teaching style in an undergraduate medical college following traditional curriculum in Pakistan. JPMA. The Journal of the Pakistan Medical Association, 63, 11, pp.1409-1414.

De Oliveira, D.F.M., Simas, B.C., Guimarães Caldeira, A.L., Medeiros, A.D.G.E.B., Freitas, M.R., Jr, J.D. \& Diniz, R. (2018) School of Medicine of Federal University of Rio Grande Do Norte: A traditional curriculum with innovative trends in medical education. Medical teacher, 40, 5, pp.467-471. 
Medical Council of India. (2018) Competency Based Under Graduate Curriculum. Available from: https://old.mciindia.org/InformationDesk/ForColl eges/UGCurriculum.aspx [Last accessed on 2019 Oct 21]

Powell, D.E. \& Carraccio, C. (2018) Toward competency-based medical education. New England Journal of Medicine, 378, 1, pp.3-5.
Shrivastava, S.R. \& Shrivastava, P.S. (2018) How to successfully implement competency-based medical education in India. Education in the Health Professions, 1, 2, pp.61. 